\title{
Unravelling single atom catalysis: The surface science approach
}

\author{
Gareth S. Parkinson*
}

The rapidly emerging field of single-atom catalysis (SAC) aims to slash the precious metal loading in heterogeneous catalysts by replacing metal nanoparticles with so-called "single-atom" active sites [1]. While there are many reports of active SAC systems, the topic remains somewhat controversial because it is very difficult to characterize a system based on adsorbed single atoms, and to distinguish between these and subnano particles [2]. In practice, most groups use aberration-corrected transmission electron microscopy (TEM) to demonstrate the atomic dispersion, sometimes supplemented by X-ray absorption near edge structure (XANES), which can rule out significant metal-metal bonding [1]. The activity of the catalyst is then tested, and although some mechanistic information can be drawn by in-situ techniques such as infrared reflection absorption spectroscopy (IRAS), the catalytic mechanism is proposed largely on the basis of theoretical calculations. Such calculations are based on an idealised model of the system, in which both the support structure and active site geometry are assumed. Thus, a one-to-one correspondence between the experimental and theoretical results is difficult to prove.

Traditionally, surface science has provided mechanistic information to understand heterogeneous catalysis. The idea is to strip away the complexity of a real catalyst and study well-defined single-crystal samples in a highly-controlled ultrahigh vacuum (UHV) environment. This way, the adsorption of individual reactants can be studied in detail, and an understanding of the basic interactions can be built up. The downside of the approach is that the highly idealised model system may not be as representative of the real catalyst as one would like, but on the upside, the model systems do strongly resemble what is calculated with density functional theory (DFT). Crucially, the structure of the model catalyst can be precisely determined from experiment, which ensures that accompanying theoretical calculations are realistic. In principle, one can obtain hard numbers for important parameters such as the adsorption energies (from thermal desorption experiments) and vibrational frequencies (from IRAS experiments), which can be used to benchmark the theoretical approach.

As one of the few techniques capable of true atomic resolution, scanning tunneling microscopy (STM) is potentially ideal to study SAC. In STM, an atomically sharp metallic tip is brought to within a few nm of a sample surface, and a bias from a few $\mathrm{mV}$ up to a few $\mathrm{V}$ is applied. Electrons tunnel into, or out of the sample depending on the applied bias, resulting in a tunneling current of the order $n A$. Since the tunneling current is exponentially dependent on the tip-sample distance, atomic-resolution images are obtained by scanning the tip over the surface and recording the tip movements necessary to maintain a constant tunneling current. There are a few important provisos, however, that must be fulfilled to perform a successful experiment. First, the support needs to be extremely flat (so that only the terminal atom of the tip interacts with the surface at any one time), which largely restricts the method to highly-oriented single crystal substrates. Second, the sample must be sufficiently conductive that a stable tunneling current can be established. The latter condition is problematic because many catalyst supports are semiconducting metal-oxides. Over the years, several strategies have been developed to circumvent the conductivity issue. Of course, some metal oxides are intrinsically conductive (e.g. $\mathrm{Fe}_{3} \mathrm{O}_{4}$ ), while others can be rendered conductive by vacuum annealing (e.g. rutile $\mathrm{TiO}_{2}$ ). If this fails, materials can be extrinsically doped (e.g. Nb-doping of anatase $\mathrm{TiO}_{2}$ or $\mathrm{SrTiO}_{3}$ ). An alternative, and now common approach [3] is to grow the oxide support as an epitaxial thin film on a metallic substrate, which provides the requisite conductivity.

To apply the surface science approach to study SAC requires that metal adatoms are stable on a well-defined metal-oxide support. This is not straightforward because, just as in real catalysts, there is a strong thermodynamic driving force for isolated adatoms to agglomerate into metallic nanoparticles. One option is to prepare a clean, flat, conductive metal oxide surface in UHV, and then sublimate metal atoms directly onto the support at low temperature. The Freund group at the Fritz Haber Institute in Berlin have specialized in such experiments in recent years, and Fig. 1 shows an example of their work on the $\mathrm{Au} / \mathrm{MgO}(100) / \mathrm{Mo}(100)$ system. Fig. 1(a) contains an STM image acquired after $\mathrm{Au}$ adatoms were sublimated onto two monolayers of $\mathrm{MgO}(100)$ at $5 \mathrm{~K}$ [4], and the system subsequently exposed to $\mathrm{CO}$. The $\mathrm{Au}$ adatoms are imaged as bright protrusions, and $\mathrm{CO}$ molecules adsorbed at the MgO step edges are imaged as dark depressions (Fig. 1(a) and (b)). Adsorption of $\mathrm{CO}$ on an $\mathrm{Au}$ adatom causes it to appear "fuzzy", because the 

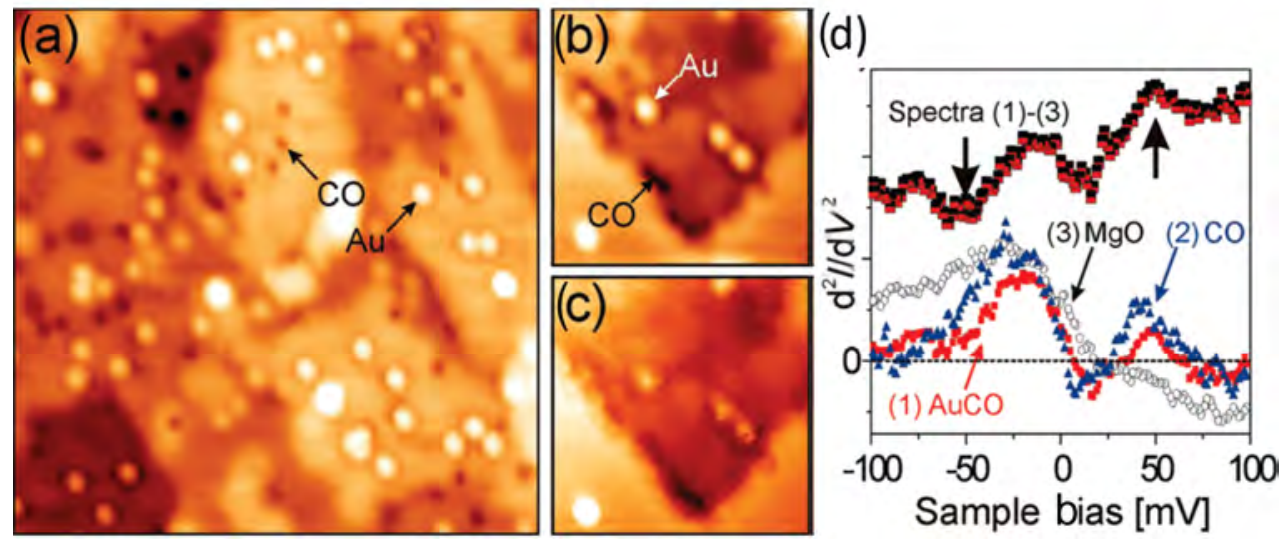

Fig. 1. (a) STM image $\left(V_{\text {Sample }}=+0.1 \mathrm{~V}, I_{\text {tunnel }}=3 \mathrm{pA}, 20 \times 20 \mathrm{~nm}^{2}\right.$ ) of single Au atoms and CO molecules on MgO thin films acquired at $5 \mathrm{~K}$. (b, c) High-resolution STM images of an identical surface region taken with (b) a metallic and (c) a CO-modified tip $\left(V_{\text {Sample }}=+0.1 \mathrm{~V}, I_{\text {tunnel }}=3\right.$ pA, $7.7 \times 7.7$ $\mathrm{nm}^{2}$ ). The fuzzy appearance of the Au species in (c) occurs because the CO of the adsorbed carbonyl interacts strongly with the tip. (d) $\mathrm{d}^{2} I / \mathrm{d} V^{2}$ spectra taken on the bare MgO surface, a single CO molecule, and an Au-CO species (set-point: $75 \mathrm{mV}, 10 \mathrm{pA}$ ). The upper curve is a difference spectrum between the $\mathrm{Au}-\mathrm{CO}$ and bare $\mathrm{MgO}$. The symmetric peak/dip structure at $+/-50 \mathrm{mV}$ is assigned to excitation of a frustrated $\mathrm{CO}$ rotational mode. Figure adapted with permission from Ref. [4]. Copyright 2010 American Chemical Society.

CO molecule interacts with the STM tip as it sweeps by on each scan line (Fig. 1(c)). Particularly interesting in this work is the use of inelastic electron tunneling spectroscopy (IETS) to study the vibrational properties of adsorbed species [5]. The $\mathrm{d}^{2} I / \mathrm{d} V^{2}$ spectra acquired above the Au carbonyl (Fig. 1(d)) exhibit a symmetric peak-dip signature at $+/-50 \mathrm{mV}$ due to the excitation of the frustrated $\mathrm{CO}$ rotation. The blue shift of this rotational mode with respect to that observed on a clean Pt surface $(+/-35 \mathrm{mV})$ is taken as evidence of the negative charge of these species, consistent with the idea that electrons tunnel from the underlying metal into the empty $6 s$ level of the Au when the oxide is so thin. These results are remarkable as, in general, IETS is rarely performed on metal oxides due to the lack of final states in the band gap for the inelastically tunneling electrons.

In recent times, the CO-stretching frequency measured in IRAS has been used to differentiate between adatoms and nanoparticles [2]. The interpretation of such frequencies is somewhat controversial [6], and an important role for surface science is to provide definitive vibrational frequencies to identify different species. The above described system, $\mathrm{Au} / \mathrm{MgO}(100)$, is an excellent example of what can be achieved, and illustrates how complex the situation can be $[7,8]$. For example, $\mathrm{Au}$ adatoms can be neutral, negatively charged, and positively charged depending on the adsorption site, and both neutral and negatively charged clusters can also exist. Moreover, the adsorption of a $\mathrm{CO}$ molecule on a neutral Au adatom on the terrace induces sufficient charge transfer from the substrate that this species appears even more red-shifted than the negatively Au charged species! Clearly, $\mathrm{CO}$ is not an innocent probe of the system, and care must be taken characterizing SAC on solely the basis of IRAS frequencies.

At this juncture I would like to highlight an exciting methodological development occurring in surface science today that can directly impact the characterisation of a model single-atom catalyst. The latest generation of low-temperature scanning-probe instruments combine non-contact atomic force microscopy (nc-AFM) and STM in one system. This removes the limitation regarding conductive supports, but also offers unprecedented resolution [9] and additional functionalities. For example, Onoda et al. [10] demonstrated a method to directly determine the Pauling electronegativity of adsorbed adatoms on Si(111) by measuring the maximum attractive force directly above. It is easy to imagine similar experiments for metal atoms adsorbed on metal oxide supports, with the different charge state of atoms in different adsorption sites (regular terrace/oxygen vacancy etc.) of particular interest.

While much can be learned from experiments at cryogenic temperatures, the resulting surface is probably not representative of a single-atom catalyst. In general, adatoms are probably not bound at regular lattice sites at elevated temperatures, and will quickly diffuse to occupy more strongly binding defect sites. Early surface science studies identified surface oxygen vacancies as nucleation sites for metal nanoparticles [11], and the first surface science study to report catalytically-active single atoms (already in 2000 [12]) proposed acetylene cyclotrimerization to be catalysed by negatively charged $\mathrm{Pd}_{1}$ species anchored at oxygen vacancies on $\mathrm{MgO}(100)$. It is important to note that some materials, e.g. the iron oxides [13], do not exhibit oxygen vacancies in the bulk when reduced, instead preferring to accommodate the non-stoichiometry with bulk Fe interstitials. As such, excess Fe is a more common surface defect than an oxygen vacancy.

Since SAC really came to the fore through the work of Flytzani-Stephanopoulos [14] and Zhang [1], surface scientists have begun to investigate the stability and reactivity of $\mathrm{Pt}_{1}$ on ceria and iron-oxide supports. Neyman and coworkers [15] proposed that $\mathrm{Pt}^{2+}$ cations could be stabilized within so-called $\mathrm{Pt}-\mathrm{O}_{4}$ nanopockets. Using a combination of STM, X-ray photoelectron spectroscopy (XPS) and DFT, Dvorak et al. [16] demonstrated that such nanopockets could exist at step edges on $\mathrm{CeO}_{2}$ (111). Specifically, they found that $\mathrm{Pt}^{2+}$ dominated for samples with a high step density (Fig. 2(g)-(i)), whereas flat, oxygen vacancy rich samples promoted the formation of metallic clusters on the terraces (Fig. 2(d)-(f)). Interestingly, alt- 

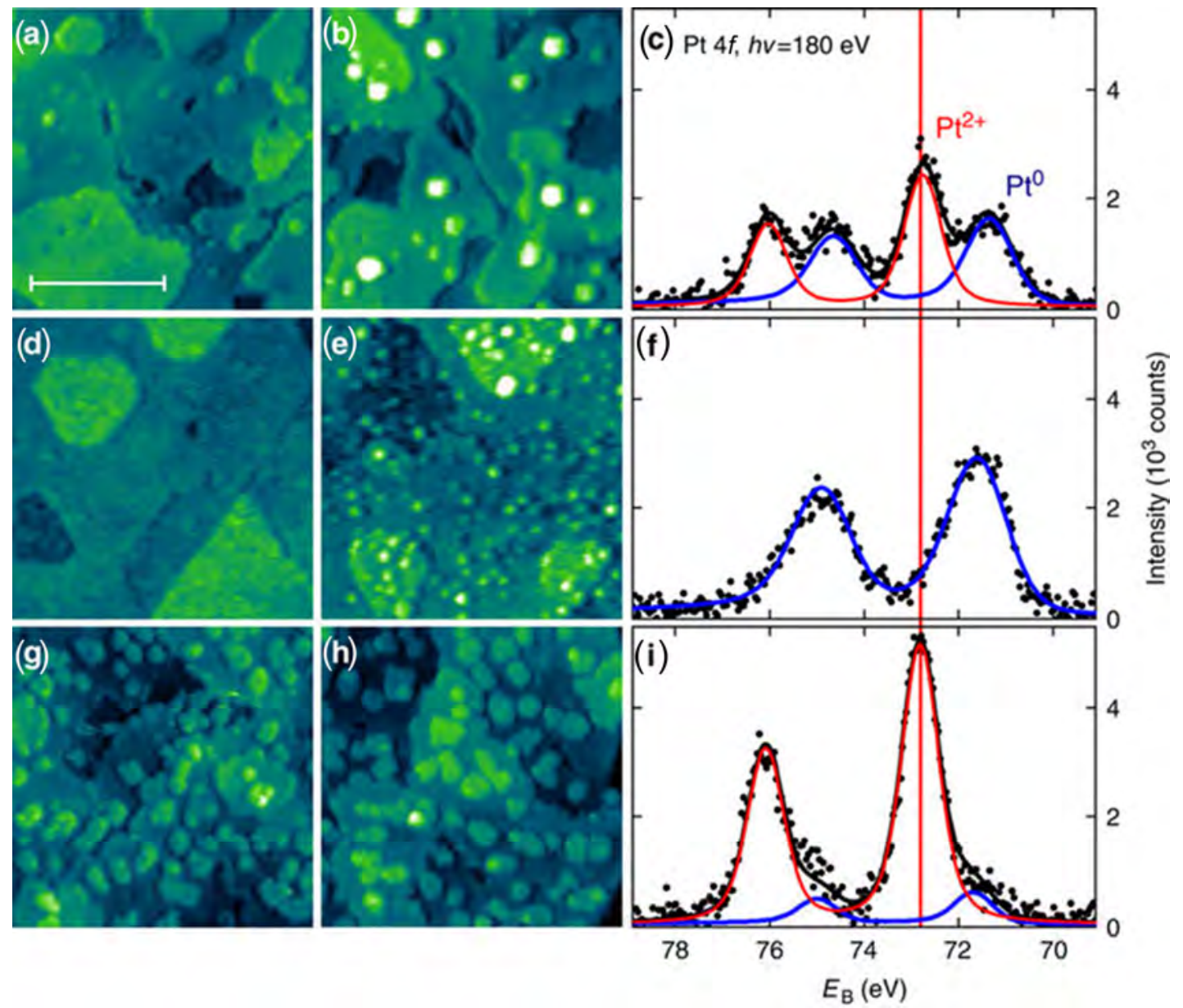

Fig. 2. Characterization of a model Pt $/ \mathrm{CeO}_{2}(111)$ catalyst by STM and XPS. The STM images $\left(45 \times 45 \mathrm{~nm}^{2}, V_{\text {sample }}=+2.5-3.5 \mathrm{~V}, I_{\text {tunnel }}=0.25-0.75 \mathrm{na}\right)$ show three sample types after deposition at room temperature (left column) and following annealing at $700 \mathrm{~K}$ in UHV (middle column). The samples are as follows: (a, b) mostly defect-free, (d, e) oxygen vacancy rich, and $(\mathrm{g}, \mathrm{h})$ high step-density. In the right column (c, f, i), corresponding Pt $4 f$ XPS spectra are shown. Fits indicate metallic $\left(\mathrm{Pt}^{0}\right.$, blue line) and ionic $\left(\mathrm{Pt}^{2+}\right.$, red line) contributions to $\mathrm{Pt} 4 f$ signal. $\mathrm{Pt}^{2+}$ clearly dominates, and is very stable, when the ceria support has a high step density. Reproduced with permission from Ref. [13]. Copyright 2016, Nature Publishing Group.

hough the $\mathrm{Pt}^{2+}$ was found to be thermally and chemically stable, it is apparently inactive for the dissociation of $\mathrm{H}_{2}$ [17], and thus ineffective for hydrogenation reactions. A full review of the findings was recently published [18], but in general, the authors conclude that $\mathrm{Pt}^{2+}$ cations do not interact strongly with adsorbates, and that subnano Pt nanoparticles are likely responsible for catalytic activity arising in this system.

Our group has largely utilized the $\mathrm{Fe}_{3} \mathrm{O}_{4}(001)$ surface as a model support because an unusual (sub)surface reconstruction [19] stabilizes arrays of adatoms (of almost any variety $[13,20]$ ) with a periodicity of $0.84 \mathrm{~nm}$ to temperatures as high as $700 \mathrm{~K}$. In the case of Pt [21], most adatoms are twofold coordinated to surface oxygen, as shown in Fig. 3(a), and DFT $+U$ calculations find them to be close to a neutral atom. In contrast to ceria, adatom stability is not solely due to an extremely strong interaction with the support, but also to kinetic limitations. Essentially, the $\mathrm{Pt}_{2}$ dimer is unstable with respect to two $\mathrm{Pt}_{1}$ adatoms on this surface, and such species rapidly decay [21]. This prevents the formation of larger clusters. STM experiments reveal that these metastable $\mathrm{Pt}$ atoms interact strongly with molecules from the gas phase. For example, CO adsorption lifts the Pt away from the support, as shown in Fig. 3(b). This species appears as a double lobed feature in STM measurements because the STM shows a time average of two symmetrically equivalent Pt-CO configurations, between which the system switches rapidly at room temperature.

One particularly advantageous aspect of the $\mathrm{Fe}_{3} \mathrm{O}_{4}(001)$ model system is that diffusion is sufficiently slow at room temperature that dynamics can be followed atom-by-atom using the STM [21]. Fig. 3(c) shows selected frames from an STM movie (in total 55 sequential STM frames recorded over the same $33 \times 30 \mathrm{~nm}^{2}$ sample area over $\approx 2.5 \mathrm{~h}$ ). The $\mathrm{Pt}_{1}$ species are imaged as bright protrusions between the rows of the $\mathrm{Fe}_{3} \mathrm{O}_{4}$ support (see Fig. 3(a) for the configuration), and are immobile. (A second, metastable $\mathrm{Pt}_{1}{ }^{*}$ site also exists, also twofold coordinated to surface oxygen, but along the surface rows instead of across.) Pt 1 -CO carbonyls form readily on CO exposure, appearing as the bright double-lobed feature described above. The weakened interaction with the oxide support allows the $\mathrm{Pt}_{1}$-CO species to diffuse across the surface, and when they meet, stable $\mathrm{Pt}_{2}(\mathrm{CO})_{2}$ dimers are formed. There are instances, such as that highlighted in the figure, where larger clusters form through the same mechanism. Interestingly, the $\mathrm{Pt}_{2}(\mathrm{CO})_{2}$ dimers break apart into two $\mathrm{Pt}_{1}$ species when the $\mathrm{CO}$ desorbs at 

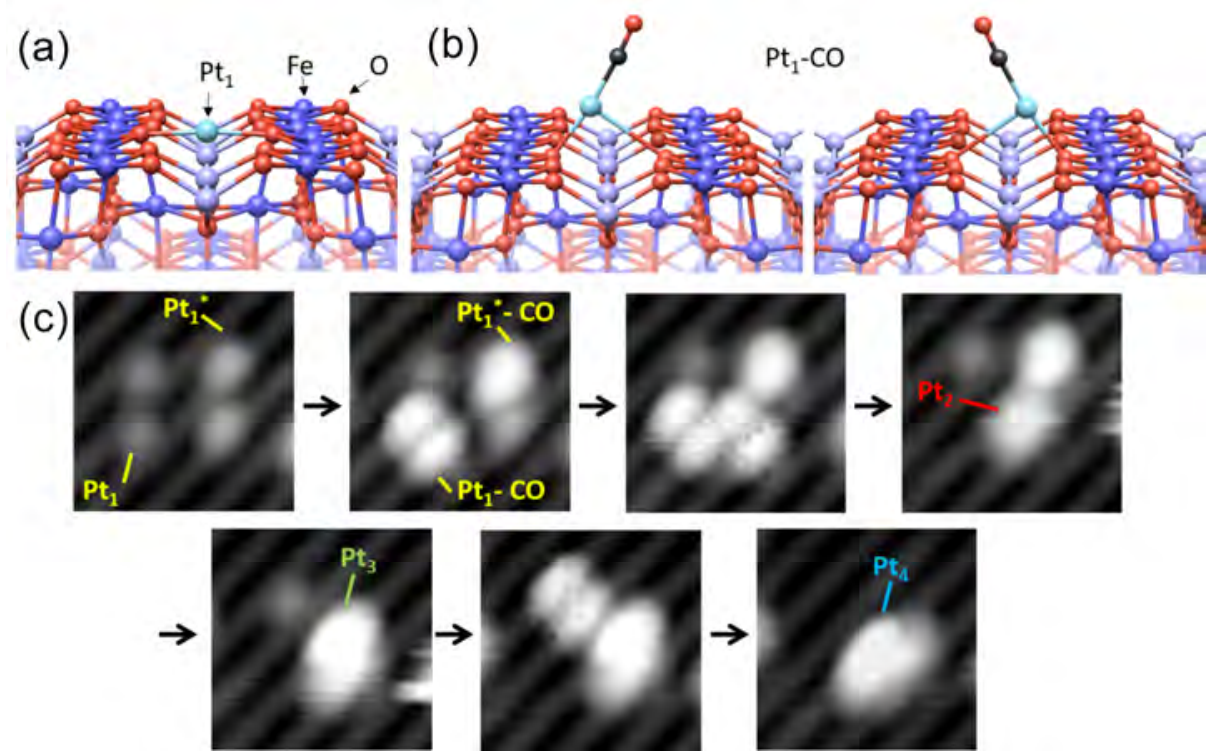

Fig. 3. CO-induced Pt diffusion and coalescence on $\mathrm{Fe}_{3} \mathrm{O}_{4}(001)-(\sqrt{2} \times \sqrt{2}) \mathrm{R} 45^{\circ}$. (a) The energetically preferred $\mathrm{Pt}_{1}$ geometry is two-fold coordinated to surface oxygen atoms across the rows. A metastable geometry (Pt1*) in which Pt is bound to two $\mathrm{O}$ atoms along the row is not shown. (b) Adsorption of a $\mathrm{CO}$ molecule lifts the Pt atom from the surface, resulting in a Pt-CO species that switches rapidly between two symmetrically equivalent configurations at room temperature. This produces a double-lobed appearance in STM. (c) STM image sequence acquired during exposure to $2 \times 10^{-10} \mathrm{mbar}$ $\mathrm{CO}$ showing the formation of a Pt tetramer: $\mathrm{CO}$ adsorption on $\mathrm{Pt}_{1}$ and $\mathrm{Pt}_{1}{ }^{*}$, mobility, and coalescence are observed atom by atom. Figure adapted from Ref. [21] with permission from the authors.

$\approx 500 \mathrm{~K}$, resulting in the recovery of the Pt adatom phase. Ultimately however, we find that the $\mathrm{Pt} / \mathrm{Fe}_{3} \mathrm{O}_{4}(001)$ system is active for $\mathrm{CO}$ and $\mathrm{H}_{2}$ oxidation through an MvK-type $\mathrm{O}_{\text {lattice }}$ abstraction at $\approx 520 \mathrm{~K}[22]$ only when subnano Pt clusters are present. Pt adatoms do not participate because they sinter too rapidly upon exposure to $\mathrm{CO}$.

As a final example, we consider the recent work of Zhou et al. [23], who successfully combined atomically-resolved STM with temperature programmed desorption (TPD) to study the reactivity of $\mathrm{Pt}$ atoms and subnano particles supported by a monolayer of $\mathrm{CuO}$ grown on $\mathrm{Cu}(110)$ (Fig. 4). The authors demonstrate that subnano clusters catalyse $\mathrm{CO}$ oxidation activity via a Mars-van Krevelen (MvK) mechanism, and that $\mathrm{Pt}$ adatoms are inactive because $\mathrm{CO}$ desorbs at $\approx 300 \mathrm{~K}$ from the carbonyl, long before there is sufficient thermal energy availa-
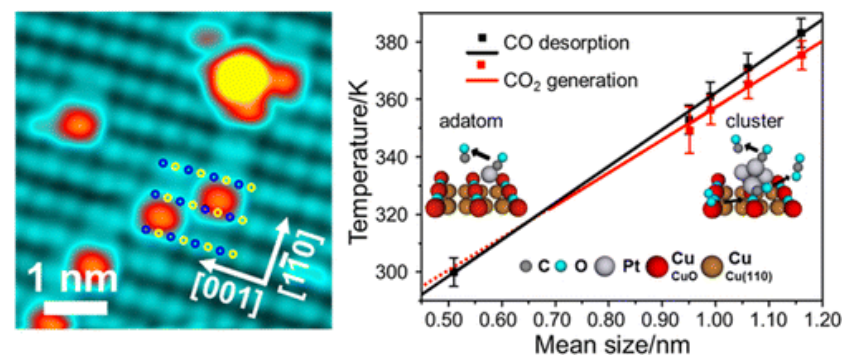

Fig. 4. STM image $\left(V_{\text {sample }}=+0.3 \mathrm{~V}\right.$, $\left.I_{\text {tunnel }}=30 \mathrm{pA}\right)$ of Pt single atoms and nanoclusters on $\mathrm{CuO}$ monolayer prepared by deposition of $0.1 \mathrm{~mL} \mathrm{Pt}$ at RT. Blue and yellow circles represent the $\mathrm{Cu}$ and $\mathrm{O}$ ions of the $\mathrm{CuO}$ support, respectively. (Right) Plots of the $\mathrm{CO}$ desorption and $\mathrm{CO}_{2}$ generation temperatures versus mean size of the Pt nanoclusters. In the case of a single Pt atom, CO desorbs before there is sufficient thermal energy to allow a MvK reaction with the underlying substrate. Figure adapted with permission from Ref. [23]. Copyright 2016 American Chemical Society. ble in the system to extract $\mathrm{O}$ from the lattice. Such weak CO binding on the Pt adatom is in stark contrast to the behaviour on the $\mathrm{Fe}_{3} \mathrm{O}_{4}(001)$ support described above. Unfortunately, it is difficult to ascertain the reason at present because no spectroscopy or DFT calculations were performed with which one could ascertain the oxidation state of the $\mathrm{Pt}_{1}$ species.

In the three examples cited above there appears to be precious little evidence to support catalytic activity of oxide supported Pt atoms. Undercoordinated, neutral Pt adatoms interact too strongly with $\mathrm{CO}$, leading to rapid sintering. On the other hand, highly coordinated $\mathrm{Pt}^{2+}$ cations do not seem to interact strongly enough with adsorbates to be catalytically active. It must be noted however, that all of the above-mentioned work was conducted under UHV conditions, and it is certainly possible that a significant pressure gap exists. Although CO desorbs from $\mathrm{Pt}_{1}$ on $\mathrm{CuO}$ at $300 \mathrm{~K}$ in a TPD experiment, at high pressures the relatively weak interaction could still be sufficient to trap some CO molecules near the surface long enough for a MvK process to occur. To investigate SAC at such conditions one needs to perform STM at high pressures and temperatures. Both situations are, in principle, relatively straightforward to achieve, and commercial setups have been available for more than a decade. Nevertheless, experiments are difficult because STM is a comparatively slow technique, and not suited to study systems with rapid diffusion. Similarly, STM at high pressure is possible, but the hard fought certainty and control offered by UHV conditions is sacrificed, and assigning the different protrusions becomes impossible. There have been notable successes [24], particularly revealing relatively large scale changes to surface morphology that can occur under reaction conditions. Unravelling the mechanisms of a single atom catalyst under reaction conditions requires a level of resolution that is 
yet to be demonstrated. At present, several groups around the world are currently working to make this reality however, and we eagerly await their results.

It seems almost premature to discuss future directions of SAC in surface science when so much basic work remains to be done. In the dream scenario, lessons learned from surface science will be used to directly improve catalytic systems, or maybe even allow the design of a new one from scratch. This ideal is exemplified in the fruitful collaboration between the Sykes and Flytzani-Stephanopoulos' groups at Tufts University. In their work on the related concept of single atom alloys (SAA) [25], a concept is typically demonstrated in UHV experiments, and the results used to design an analogous nanoparticle system, which is then tested for catalytic activity [26]. These articles benefit hugely from the dual-pronged approach, and in my opinion, this strategy should be applied where possible as we attempt to understand the reactivity of single-atom catalysts based on oxide supports.

\section{Acknowledgements}

GSP acknowledges funding from the Austrian Science Fund START prize (Y 847-N20), and thanks Prof. Ulrike Diebold (TU Wien) for critically reading the manuscript.

\section{Gareth S. Parkinson}

Institute of Applied Physics, TU Wien, Vienna, Austria

E-mail: parkinson@iap.tuwien.ac.at

Received 24 May 2017

Published 05 September 2017

DOI: 10.1016/S1872-2067(17)62878-X

\section{References}

[1] B. T. Qiao, A. Q. Wang, X. F. Yang, L. F. Allard, Z. Jiang, Y. T. Cui, J. Y. Liu, J. Li, T. Zhang, Nat. Chem., 2011, 3, 634-641.

[2] K. Ding, A. Gulec, A. M. Johnson, N. M. Schweitzer, G. D. Stucky, L. D. Marks, P. C. Stair, Science, 2015, 350, 189-192.

[3] H. J. Freund, G. Pacchioni, Chem. Soc. Rev., 2008, 37, 2224-2242.

[4] B. Yang, X. Lin, H. J. Gao, N. Nilius, H. J. Freund, J. Phys. Chem. C, 2010, 114, 8997-9001.

[5] B. C. Stipe, M. A. Rezaei, W. Ho, Science, 1998, 280, 1732-1735.
[6] H. A. Aleksandrov, K. M. Neyman, K. I. Hadjiivanov, G. N. Vayssilov, Phys. Chem. Chem. Phys., 2016, 18, 22108-22121.

[7] M. Sterrer, M. Yulikov, T. Risse, H. J. Freund, J. Carrasco, F. Illas, C. Di Valentin, L. Giordano, G. Pacchioni, Angew. Chem. Int. Ed., 2006, 45, 2633-2635

[8] M. Sterrer, M. Yulikov, E. Fischbach, M. Heyde, H. P. Rust, G. Pacchioni, T. Risse, H. J. Freund, Angew. Chem. Int. Ed., 2006, 45, 2630-2632.

[9] L. Gross, F. Mohn, N. Moll, P. Liljeroth, G. Meyer, Science, 2009, $325,1110-1114$

[10] J. Onoda, Y. Sugimoto, M. Ondráček, P. Jelínek, Nat. Commun. 2017, 8, 15155 .

[11] E. Wahlström, N. Lopez, R. Schaub, P. Thostrup, A. Rønnau, C. Africh, E. Lægsgaard, J. K. Nørskov, F. Besenbacher, Phys. Rev. Lett., 2003, 90, 026101/1-026101/4.

[12] S. Abbet, A. Sanchez, U. Heiz, W. D. Schneider, A. M. Ferrari, G. Pacchioni, N. Rösch, J. Am. Chem. Soc., 2000, 122, 3453-3457.

[13] G. S. Parkinson, Surf. Sci. Rep., 2016, 71, 272-365.

[14] Q. Fu, H. Saltsburg, M. Flytzani-Stephanopoulos, Science, 2003, 301, 935-938.

[15] A. Bruix, Y. Lykhach, I. Matolínová, A. Neitzel, T. Skála, N. Tsud, M. Vorokhta, V. Stetsovych, K. Ševčíková, J. Mysliveček, R. Fiala, M. Václavů, K. C. Prince, S. Bruyère, V. Potin, F. Illas, V. Matolín, J. Libuda, K. M. Neyman, Angew. Chem. Int. Ed., 2014, 53, 10525-10530.

[16] F. Dvořák, A. Tovt, M. Vorokhta, I. Matolínová, J. Mysliveček, V. Matolín, M. Farnesi Camellone, N. D. Tran, F. R. Negreiros, S. Fabris, T. Skála, Nat. Commun., 2016, 7, 10801.

[17] Y. Lykhach, A. Neitzel, J. Libuda, A. Figueroba, M. F. Camellone, F. R. Negreiros, S. Fabris, T. Skala, M. Vorokhta, N. Tsud, V. Matolin, K. C. Prince, K. M. Neyman, Phys. Chem. Chem. Phys., 2016, 18, 7672-7679.

[18] Y. Lykhach, A. Bruix, S. Fabris, V. Potin, I. Matolinova, V. Matolin, J. Libuda, K. M. Neyman, Catal. Sci. Technol, 2017.

[19] R. Bliem, M. Setvin, O. Gamba, J. Pavelec, M. Schmid, U. Diebold, G. S. Parkinson, E. McDermott, P. Blaha, P. Ferstl, M. A. Schneider, L. Hammer, Science, 2014, 346, 1215-1218.

[20] R. Bliem, J. Pavelec, O. Gamba, E. McDermott, Z. Wang, S. Gerhold, M. Wagner, J. Osiecki, K. Schulte, M. Schmid, P. Blaha, U. Diebold, G. S. Parkinson, Phys. Rev. B, 2015, 92, 075440/1-075440/9.

[21] R. Bliem, J. Hulva, J. Pavelec, O. Gamba, M. Schmid, U. Diebold, G. S. Parkinson, J. E. S. van der Hoeven, P. E. de Jongh, P. Blaha, Proc. Natl. Acad. Sci. USA, 2016, 113, 8921-8926.

[22] R. Bliem, O. Gamba, J. Pavelec, M. Schmid, U. Diebold, G. S. Parkinson, J. van der Hoeven, P. E. de Jongh, A. Zavodny, Angew. Chem.

\section{Graphical Abstract}

Chin. J. Catal., 2017, 38: 1454-1459 doi: 10.1016/S1872-2067(17)62878-X

Unravelling single atom catalysis: The surface science approach

Gareth S. Parkinson*

TU Wien, Austria

This perspective discusses how studies of idealised model systems can shed light on the fundamental mechanisms of single-atom catalysis. The image shows $\mathrm{Au}$ adatoms supported by $\mathrm{Fe}_{3} \mathrm{O}_{4}(001)$.

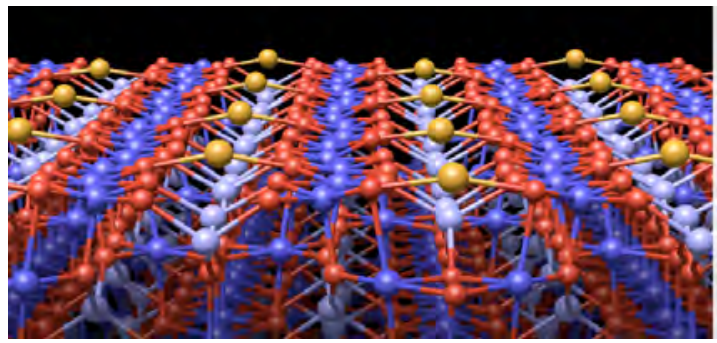


Int. Ed., 2015, 54, 13999-14002.

[23] X. Zhou, W. S. Yang, Q. W. Chen, Z. H. Geng, X. Shao, J. L. Li, Y. F. Wang, D. X. Dai, W. Chen, G. Q. Xu, X. M. Yang, K. Wu, J. Phys. Chem. C, 2016, 120, 1709-1715.

[24] F. Tao, S. Dag, L. W. Wang, Z. Liu, D. R. Butcher, H. Bluhm, M. Salmeron, G. A. Somorjai, Science, 2010, 327, 850-853.
[25] G. Kyriakou, M. B. Boucher, A. D. Jewell, E. A. Lewis, T. J. Lawton, A. E. Baber, H. L. Tierney, M. Flytzani-Stephanopoulos, E. C. H. Sykes, Science, 2012, 335, 1209-1212.

[26] F. R. Lucci, M. D. Marcinkowski, E. C. H. Sykes, J. Liu, M. Yang, M. Flytzani-Stephanopoulos, L. F. Allard, Nat. Commun., 2015, 6, 8550.

\section{揭秘单原子催化: 表面科学方法}

\section{Gareth S. Parkinson*}

维也纳工业大学应用物理研究所, 维也纳, 奥地利

摘要: 理解单原子催化的基本机理对于设计高性能和高稳定性的催化剂体系至关重要. 然而, 这是个有待解决的问题, 因 为用现有的实验技术来表征单原子催化活性位极端困难. 在过去的 40 年里, 表面科学为理解多相催化提供了基础, 但是有 关反应温度下、已知结构金属氧化物上稳定的金属原子的模型体系罕见报道. 本视角讨论了已知的、吸附在模型金属氧 化物表面上的、孤立的金属原子, 并探讨了如何利用这些信息去理解单原子催化. 一个关键的问题是, 尽管在表面科学研 究中的高度理想化的模型体系可能无法代表真实反应条件下的催化剂, 但是它们与采用理论模拟计算得出的模型非常相 似. 因此, 表面科学有望成为评估单原子催化模型的方法. 更令人兴奋的是, 几个研究组已经发展出在升温条件下金属吸 附原子仍保持稳定的模型体系. 但到目前为止, 还不能清楚地解释催化活性. 最后, 本文简要地讨论了在真实反应条件下 扫描隧道显微镜的实验前景.

关键词: 单原子催化; 扫描隧道显微镜; 表面科学; 无触点原子力显微镜; 单原子催化模型

收稿日期: 2017-05-24. 接受日期: 2017-06-26. 出版日期: 2017-09-05.

*通讯联系人. 电子信箱: parkinson@iap.tuwien.ac.at

基金来源：奥地利科学基金金奖(Y 847-N20).

本文的英文电子版由Elsevier出版社在ScienceDirect上出版(http://www.sciencedirect.com/science/journal/18722067). 